\title{
Secondary Students' Perceptions of Their Engagement in a Correcting Process
}

\author{
Trang Thi Doan Dang ${ }^{1}$ \\ ${ }^{1}$ Faculty of Education, Monash University, Australia \\ Correspondence: Trang Thi Doan Dang, Australia. E-mail: doantrangmc71@gmail.com
}

Received: August 13, 2021

Accepted: September 22, $2021 \quad$ Online Published: November 26, 2021

doi:10.5539/ies.v14n12p78

URL: https://doi.org/10.5539/ies.v14n12p78

\begin{abstract}
This study draws on mediated learning experience (MLE) theory to contextualize the correcting process within the sociocultural dimension of the teacher's intervention and collaborative learning to facilitate student engagement with discovering, correcting, and rewriting practices. This correcting process was administered to eight mixed-ability groups of Vietnamese secondary students $(n=31)$ to investigate students' perceptions of their engagement in the process from both quantitative and qualitative perspectives that have been under-researched so far. The statistical analysis of a closed-ended questionnaire shows that students strongly agreed with the practices and effectiveness of the process, accuracy improvement, approach preferences, and learning motivation. Eight students' responses to semi-structured interviews elaborated on the benefits and disadvantages of group-correction and the significance of targeting errors, and on each correcting phase. While students' responses satisfied MLE's criteria, their perceptions of the limitations of group-correction somewhat qualified the way reciprocity occurred. The findings suggest offering students opportunities to act on language issues in their writing and confirm the usefulness of engagement with correction-feedback practices from which implications for L2 writing and further research are discussed.
\end{abstract}

Keywords: mediated learning experience, engagement, feedback, collaborative learning

\section{Introduction}

Feedback practices have been a central focus of numerous second language (L2) writing studies. Previous research has debated the impact of teacher feedback on second language (L2) writing improvement (Bitchener, 2008; Ferris, 1999; Truscott, 1996, 2007). There has also been a discussion of whether teacher feedback or peer feedback leads to the development of L2 students' writing ability (see Ruegg, 2015). Various opinions about the role of feedback have extended research into students' perceptions of teacher and peer feedback (Ferris, 1995, 2003, 2011; Lee, 2005, 2008, 2015; Ruegg, 2017). Although a few studies have recently explored student beliefs and engagement with feedback and written corrective feedback (WCF) (Han, 2017; Storch \& Wigglesworth, 2010), little research has investigated students' perceptions of their engagement in a correcting process.

Engagement is one of the most important components in L2 writing despite having a wide range of definitions. In corrective feedback, the term 'engagement', which is referred to as learners' responses to feedback, is the most crucial variable contributing to students' learning outcomes and development (Ellis, 2010; Han \& Hyland, 2019). Engagement is also described as processing direct and indirect feedback (Qi \& Lapkin, 2001; Storch \& Wigglesworth, 2010) and as editing and revising practices (Ferris et al., 2013; Hyland, 2003). Previous research conducted in university contexts has reported that engagement with WCF is affected by students' beliefs, learning experiences and context (Han \& Hyland, 2015), and their language ability (Zheng \& Yu, 2018). However, students' perceptions of their engagement in a correcting process have rarely been discussed in the literature on L2 writing feedback or explored in secondary schools in Vietnam. Given the importance of engagement with WCF, scholars suggest providing students with opportunities to locate and work on their own errors through teachers' feedback (Erlam, Ellis, \& Batstone, 2013; Lee, 2009) and contextualizing feedback practices in a supportive and interactive learning environment (Ur, 1996). The present study therefore draws on mediated learning experience (MLE) theory to operationalize the correcting process (CP) in a scaffolded learning environment in which student engagement is facilitated by the teacher's intervention and collaboration with peers.

Investigating students' perceptions of their engagement in the CP through the lens of MLE is beneficial. Learner beliefs in or views on learning refer to what learners perceive or think about learning that may have a substantial 
impact on their L2 learning processes and outcomes (Barcelos, 2003). Contextualizing the CP within the MLE framework is valuable for enhancing student engagement as learning is mediated by interaction and collaboration (Lee, 2015), and students' responsiveness to the teacher's mediational strategies enable them to modify learning features (Feuerstein \& Feuerstein, 1991). Thus, the present study uses MLE as a methodology of intervention via the teacher mediation and peer collaboration and as an analytical framework to analyze students' responses to semi-structured interviews. This paper describes engagement as students' responsive actions to the teacher mediation, the $\mathrm{CP}$ as feedback-correction practices, and feedback as the teacher's and/or peers' oral or written forms of comments on other students' use of language and ideas in their written texts.

This paper discusses data from a closed-ended questionnaire and the semi-structured interviews that were used to investigate students' perceptions of their engagement in the correcting process and identifies whether their perceptions addressed MLE's criteria.

\section{Theoretical Background}

\subsection{Mediated Learning Experience (MLE) and the Collaborative Correcting Process}

Mediated learning, as a sociocultural construct, emphasizes that learning takes place under adults' guidance and in interaction and collaboration with peers within a specific context. This mediated learning orientation can be viewed through Vygotsky's zone of proximal development (ZPD; Vygotsky, 1978) and Feuerstein's MLE theory (Feuerstein \& Feuerstein, 1991). The present study uses MLE theory as it highlights that interaction among learners, the mediator, and learning activities must satisfy three main criteria: intentionality and reciprocity, transcendence, and mediation of meaning. Feuerstein and Feuerstein (1991) consider learning of a young learner as constituted by an adult's intervention, the adult's specific activities to facilitate the learner's learning as mediated learning experiences, and the adult as a mediator. Drawing on the contextual and interactional concepts of human cognitive development, Williams and Burden (1997) later viewed language learning development as a process in which teachers, learners, and tasks interact with each other. These variables are important agents in collaborative learning, which is defined as group-based learning or learning together (Ellis, 2003), and promotes learning through social and cognitive dimensions (Fisher, 2005).

While using mixed-ability groups in collaborative learning is beneficial for peer collaboration and interaction, it entails a common shortcoming. Grouping students with mixed-ability levels may offer students a peer-tutoring learning environment; for example, capable students can tutor peers by explaining difficulties, and in return, less capable peers can learn from and be motivated by peers. These learning features foster interdependency and maximize strategies for learning from and teaching others, as each individual cares about and attempts to foster mutual learning (Fisher, 2005; Jacobs, 2006). However, one area of concern is the limited participation of low-ability students and the dominance of high-ability students (Poole, 2008).

Applied to feedback-correction practices, this study refers to intentionality as the teacher's scaffolding strategies, such as eliciting corrections from students via questions and answers and/or providing indirect or direct feedback, clues, and suggestions to facilitate student engagement in the $\mathrm{CP}$, which is also a scaffolded correcting design. Reciprocity focuses on the interactive and collaborative practices of correction that aim to maximize students' responses to feedback to process gaps. Transcendence refers to learners' ability to transfer knowledge of correction to the rewriting of the texts or for using language features correctly in the rewritten texts. Finally, mediation of meaning is seen as an effective accomplishment, mediated by students' responsive actions to discover and correct gaps and rewrite the corrected texts.

\subsection{Brief Review of Feedback Research into Learners' Perceptions}

Student perceptions of teacher feedback have long been researched in L2 writing studies, yet these have reported inconclusive findings. Students perceived that the teacher's written corrections and comments helped improve their writing accuracy (Ferris, 1995; Kim, Choi, Kang, Kim, \& Yun, 2020; Montgomery \& Baker, 2007; Saito, 1994). In particular, Malaysian university students acknowledged that teacher feedback on content and organization of their written texts is more useful than feedback on vocabulary and grammar (Vasu, Ling, \& Nimehchisalem, 2016). Tasdemir and Yalcin Arslan (2018) also found that Turkish EFL students' preferred frequent teacher feedback on common and major errors to infrequent feedback on minor ones, and they also favored teacher direct feedback, explanations, and elicitation. However, Westmacott's study (2017) found that of the six university student participants, two preferred teacher direct corrective feedback because of their learning preferences and difficulties in responding to feedback appropriately. In contrast, the other four students favored teacher's indirect method such as underlining and coding feedback, which might help them manage the correction process, and thus they were able to modify their writing. However, the learning context, the instructional practice, and students' individual differences are factors affecting students' views on teacher feedback (Lee, 2008; 
Westmacott, 2017). This highlights the need to engage students with feedback integrated into an instructional correcting process to investigate their perceptions of their engagement with this practice.

Comparative research into teacher and peer feedback practices in EFL contexts reports contentious findings. Secondary students in Hong Kong in the study of Tsui and $\mathrm{Ng}$ (2000) believed that peer feedback could strengthen their sense of audience, ownership, and collaboration. Similarly, Ruegg (2017) found that Japanese students in the peer-feedback group perceived the usefulness of asking their peers about learning difficulties and reading peers' writing, while students in the teacher-feedback group were concerned about insufficient time to revise their drafts. However, Chinese secondary students in Hong Kong valued teacher comments highly, though some preferred both teacher and peer feedback; according to them, peer feedback could be useful for triggering goal orientations, task interest, and writing improvement (Lee, 2015). University students in Malaysia perceived that teacher feedback is as useful as peer feedback (Vasu et al., 2016). Similarly, other studies found that learners preferred the combination of peer work together with teacher involvement (Dang, 2016; Yang, Badger, \& Yu, 2006; Zhao, 2014). Students' favoring of the joint work between the teacher and peers provides the basis for the present study's correcting design conducted via collaborative learning and the teacher's intervention.

Although previous studies have provided background for the present study, little research has investigated students' perceptions of their engagement in the CP. The present study extends the scope of feedback practices in two directions, by integrating forms of feedback into the $\mathrm{CP}$, and by operationalizing the $\mathrm{CP}$ within the social dimension of the teacher's feedback together with peer collaboration.

\section{Methodology}

\subsection{Design and Research Questions}

As explained, the CP was administered to eight mixed-ability groups of secondary students $(n=31)$ to investigate students' perceptions of their engagement with the process from both quantitative and qualitative perspectives. While the former surveyed students' views on the correcting process they had experienced via a 5-point Likert-type scale questionnaire (see details in Appendix A), the latter further explored students' opinions about the process through semi-structured interviews. Data from in-depth interviews were used to elaborate on students' responses to the closed-ended questionnaire. The study sought answers to the following research questions.

1) What are students' evaluations of correction, their feedback preferences, and their perceptions of the practices and consequences of the correcting process?

2) What are students' opinions about the collaborative discovering, correcting, and rewriting phases? Do their perspectives address MLE's criteria?

\subsection{Context and Participants}

The study was conducted at a senior secondary school in Ho Chi Minh City, Vietnam over an eight-week period. As a researcher, I explained the purpose, procedures, learning activities, and each type of instrument to invite students to participate in the study. Upon students' agreement, their parents signed the Consent Forms, as students were under 18. The participating students were Grade 10 students aged 16 who had spent five years learning English as a compulsory subject. Students $(N=31)$ were conveniently chosen based on their scores in the first semester English exam (see Appendix B). They were chosen because English is not their major subject, and they had received the same allocated time of learning English as the other classes in different schools. Thirty-one students were divided into eight mixed-ability groups (Groups 1-8), and members of each group were purposefully assigned according to their scores, ranging from low: $0-4.75$, fair: 5-6.75, good: $7-8.75$, and excellent: 9-10. Assigning students with mixed-ability levels aimed to create a peer tutoring learning environment as advanced students could support less capable students (Jacobs, 2006), which could strengthen students' ability to learn from and teach others (Fisher, 2005).

The eight groups were instructed to engage in writing and correcting phases by an English teacher. The teacher (not the researcher), who had 14 years' experience in teaching English skills, instructed the students to write four letters and four descriptions (Appendix C) and to engage in the correcting intervention. Six writing topics were taken from the English textbook (Hoang, Hoang, Do, \& Nguyen, 2006), and two picture descriptions were adopted from Ur (2009). The researcher, who had been a teacher of English for over 20 years in this secondary school before commencing her PhD study, delivered the questionnaire to 31 students and interviewed eight representative students after the intervention. 


\subsection{Correcting Treatment and Categories of Gaps}

Discovering, correcting, and rewriting phrases are situated in a socially mediated learning context in ways that could maximize student engagement (see Table 1). This scaffolded teaching-learning process was characterized by two aspects. The first was its emphasis on sequencing tasks that gradually moved from lower to higher levels of learning concepts to involve a range of groups of students. The second was the group-based learning paradigm, which was likely to equip students with certain skills in collaborating and interacting with the teacher and peers. From the perspective of MLE, experience in collaborating and interacting with the mediator and advanced peers enables students to build up their own learning propensity (Feuerstein \& Feuerstein, 1991). In other words, individuals' experience of the correcting process is formed through the guided learning channels, and thus students are believed to be able to modify their own learning.

The teacher used several methodological strategies to engage the eight groups in the correcting process. She first delivered the same correction guide (Appendix D) and selected written texts with three types of gaps to the eight groups. The preselected texts were anonymous so that student writers would not be uneasy when their written texts were shown. She then explained the aims and procedures of the process to the whole class and asked each group to select a group leader. To minimize levels of empowerment between capable students and less-capable peers, she encouraged the leaders to coordinate group work, assist and motivate individuals to participate in group discussion. She also asked individuals to participate in their group discussion by sharing ideas with peers to process gaps and asking and responding to peers' questions to complete their learning tasks. In addition, she mediated students' engagement by providing indirect feedback and clues and/or asking guiding questions while they were working in groups and upon their groups' presentations.

The procedures and aims of the process were as follows. The discovering and correcting practices emphasize learning by discovering and solving problems, while the rewriting task extends reflective learning by rewriting and comparing practices. The eight groups were first instructed to attend, locate, identify, and correct grammatical errors and nongrammatical issues in their written texts. For example, capable students discussed, explained, and shared solutions to treat errors with low-ability peers within their groups to promote peer collaboration. Then, some groups were invited to present or share their discoveries and corrections to the whole class and with other groups that offered all students opportunities to proofread peers' corrections, give feedback, and ask for clarifications. In doing so, low-ability students can learn from capable peers' corrections and explanations, and in return, capable students might benefit from explaining their corrections to peers and providing and responding to peers' feedback. After that, the eight groups practiced rewriting the corrected texts and compared the modified output with the original draft within groups, which was followed by groups' presentations and/or sharing practices across groups. These tasks aimed to motivate students to distinguish between the correct and incorrect renditions and monitor or notice the gaps and their modifications that sought to make the revised texts more comprehensible.

The correcting process targeted the incorrect use of the present and past tenses and conjunctions "because", "although", and "but", as well as feedback on irrelevant ideas between the topic and supporting sentences and/or a missing topic sentence. The grammatical errors were chosen because the writing topics signalled the use of the present and/or past tense and text coherence. The objective of a written paragraph, as suggested in the English curriculum, was to forge clear links between the ideas signalled by the topic sentence, the supporting ideas and/or the concluding sentence. These grammatical errors and nongrammatical issues are described as "gaps" in this paper. 
Table 1. Feedback-correction phases

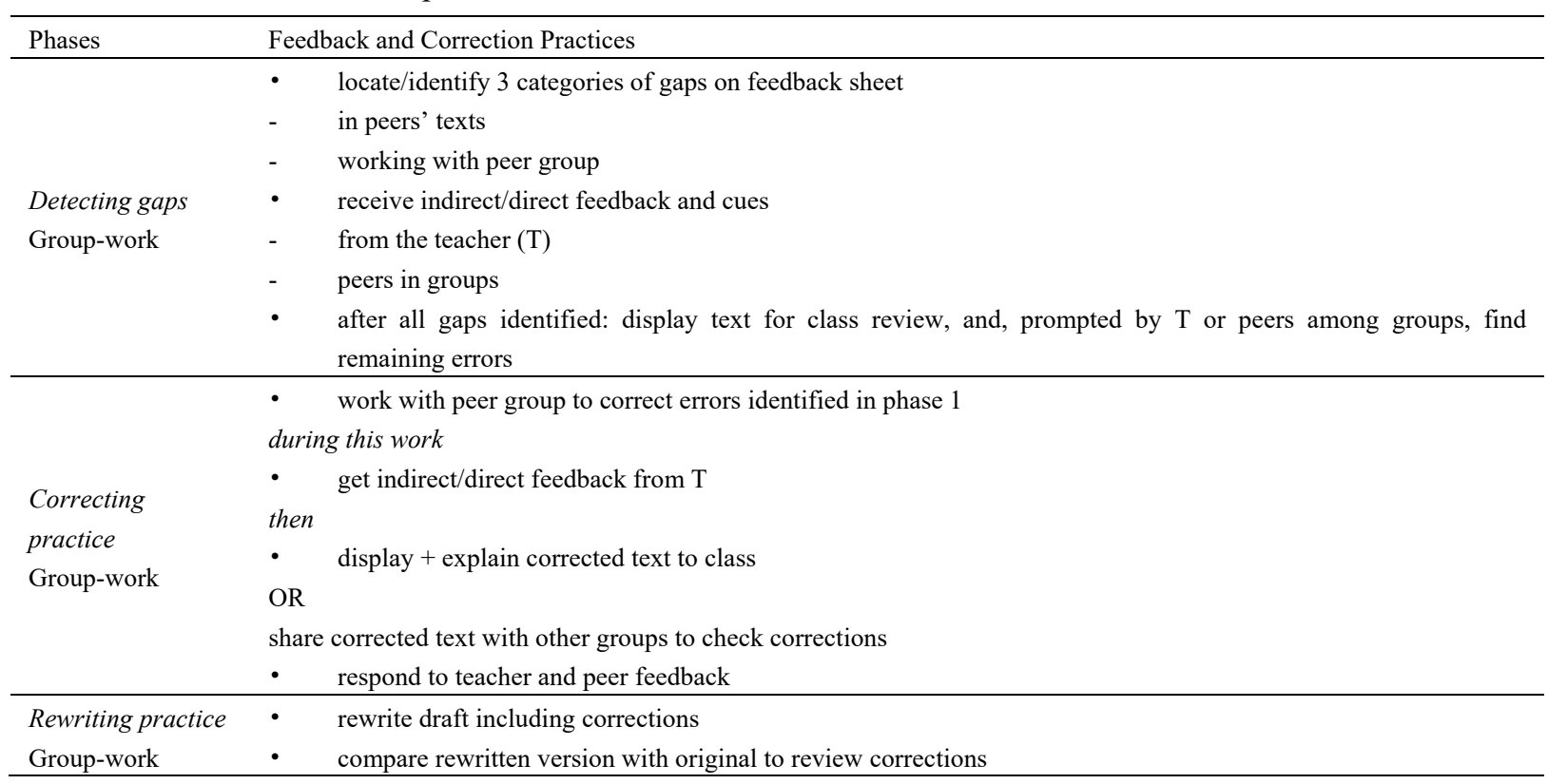

\subsection{Instruments and Analysis}

A closed-ended questionnaire on a 5-point Likert-type scale was designed along three main themes: evaluation of effectiveness, approach preference, and practices and consequences. These themes were developed conceptually and categorized into 15 statements in total (1-5A-K; see Appendix A). Although the questionnaire was written in both English and Vietnamese (the students' first language), the Vietnamese version was delivered to students to ensure that the respondents would be able to answer the questions accurately. The questionnaire was adapted from an instrument designed to investigate the effects of teacher and peer feedback, with a reliability of 0.696 (Ruegg, 2014). To address the present study's aim and scope, the instrument was revised and piloted. The questionnaire was administered to a pilot class of 41 students, after conducting the correcting phases. The researcher reviewed the students' responses and then worked on each item of the questionnaire with the students and the teacher to ensure its clarity and relevance to the correcting tasks. The researcher modified items 5D, G, H and K based on comments given by the students and the teacher.

The statistical test and descriptive statistics were adopted to analyze the 31 responses to the questionnaire. The analysis of these responses indicated a reliability of .73, considered a reasonable level (Leech, Barrett, \& Morgan, 2005). Descriptive statistics were used to measure an average level of students' evaluation of correction, their approach preferences, and their perceptions of the practices and consequences of the process through a summary of percentage and mean.

The aims of the follow-up semi-structured interview were as follows. As described, the interviews were conducted with eight volunteer students; each student represented a different group. The interviews collected students' ideas about four main factors: (1) evaluation of correction; (2) the three correcting phases; (3) types of gaps; and (4) correcting methods. This paper reports examples of responses to extensive data gained from the questionnaire. The interviews were conducted in the students' first language (Vietnamese), recorded, transcribed and translated, and the interviewees' names presented in this paper are pseudonyms.

A deductive method was used to analyze data; the students' responses to the interviews were analyzed according to the criteria of the MLE framework. For example, the researcher designed a table to code and analyze the interview data with reference to specific descriptions of each criterion of MLE (Appendix E). Using this table to guide the analysis of the data helped the researcher avoid her expectations and thoughts, visualize the respondents' ideas, and link them with theoretical concepts of MLE. Then, the analysis was reviewed by the researcher and her PhD supervisors who are experts in the field.

\section{Results}

The two research questions investigated students' perceptions of their engagement with feedback and correction integrated into the correcting process (CP). As the second research question further explored the students' opinions 
about the collaborative $\mathrm{CP}$, examples of their responses to the interview are used to expand on the results of the questionnaire that are presented according to themes below.

The students responded positively to the 15 statements of the questionnaire categorized into three themes: evaluation of effectiveness, approach preferences, and practices and consequences. The students' responses to the semi-structured interviews elaborated on the benefits and disadvantages of group correction, the significance of targeting errors, and each correcting phase. Although their perceptions satisfied MLE's criteria, the perceived limitations of group-correction somewhat qualified the way MLE's reciprocity occurred.

\subsection{Theme 1: Evaluation of Effectiveness}

The results shown in Table 2 reports the high frequency and mean of students' responses to the evaluation of the effectiveness of correction. Students perceived the effectiveness of correction as very good: $68 \%$, and excellent: $32 \%$. In addition, the percentage of students who evaluated the positive impact of correction on their correcting ability (93\%) and writing accuracy (97\%) was considerably higher than those who considered it as not so good; 7\% and 3\% respectively. This indicates that most students rated highly the usefulness of the collaborative correcting process they had experienced. Although this finding is supported by previous research reporting students' acknowledgement of the effects of teacher feedback on accuracy improvement (Ferris, 1995; Kim et al., 2020; Montgomery \& Baker, 2007; Saito, 1994), it elaborates on the teacher's mediation and peer collaboration. The findings are supplemented by the eight students' reported benefits of correction, which are in line with MLE's transcendence. For example, Anh acknowledged that she could "consolidate present and past tenses and use conjunctions to link ideas in a piece of writing". Moreover, Anh and Khoa reported that they could apply to their first language the strategies they had used to amend the topic and supporting sentences in English. Anh said: “...[I] know how to connect with Vietnamese literature writing, especially the topic sentence and its supporting ideas".

Table 2. Students' evaluation of effectiveness of correction $(N=31)$

\begin{tabular}{lcccc}
\hline \multirow{2}{*}{ Statements } & & \multicolumn{3}{c}{ Descriptive statistics } \\
& & Frequency & Percent & Mean \\
\hline \multirow{2}{*}{ 1. Effectiveness of correcting errors } & Very good & 21 & 67.7 & \multirow{2}{*}{4.32} \\
& Excellent & 10 & 32.3 & \\
\hline \multirow{3}{*}{ 2. To enhance correcting ability } & Not so good & 2 & 6.5 & \\
& Good & 16 & 51.6 & \multirow{2}{*}{3.35} \\
& Very good & 13 & 41.9 & \\
\hline \multirow{3}{*}{ 3. To enhance writing accuracy } & Not so good & 1 & 3.2 & \\
& Good & 14 & 45.2 & \multirow{2}{*}{3.48} \\
& Very good & 16 & 51.6 & \\
\hline
\end{tabular}

\subsection{Theme 2: Approach Preference}

The second theme of the questionnaire surveyed students' preferences for correcting approaches. The statistical analysis shown in Table 3 indicates that while the majority of students preferred "group and teacher correction" $(68 \%)$ and "group correction" $(26 \%), 6 \%$ of students favored "teacher correction". The fact that the teacher facilitated students to work in groups to identify gaps, correct the identified gaps and to rewrite the texts might explain this result, which is further elaborated by six students' explanations. Anh stated: "We had opportunities to work with friends to correct the identified gaps, and we learnt the corrections from friends in our group and other groups through their presentations. We received useful comments from the teacher and friends." These responses satisfied MLE's intentionality and reciprocity. While this finding clarifies empirical evidence of recent studies discussing the impact of peer feedback on students' higher level of revisions (Hentasmaka \& Cahyono, 2021), it also highlights the usefulness of teacher feedback.

Table 3. Students' preferences for the correcting approaches $(N=31)$

\begin{tabular}{lcccc}
\hline \multirow{2}{*}{ Statements } & & \multicolumn{3}{c}{ Descriptive statistics } \\
\cline { 3 - 5 } & & Frequency & Percent & Mean \\
\hline \multirow{3}{*}{ 4. Approach preferences } & Teacher & 2 & 6.5 & \\
& Group and teacher & 21 & 67.7 & 4.13 \\
& Small groups & 8 & 25.8 & \\
\hline
\end{tabular}


However, respondents to the semi-structured interview elaborated that group-correction resulted in some issues that needed support from the teacher. For instance, some individuals did not fully engage in their group-work since they could not reconcile their ideas with those of peers, and thus, group-correction required more time, as Han, Nhu, Lam, and Tu explained. An example is that "some members did not participate in correction", and thus "individuals within groups should have closer collaboration and reconciliation" (Nhu). Nhu acknowledged that, to this end, "the teacher's intervention in groups to distinguish between correctness and incorrectness is very beneficial". This finding shows that although unequal contributions to group-work does not fully qualify MLE's reciprocity, the teacher's support is evidence of MLE's intentionality.

\subsection{Theme 3: Practices and Consequences of the Correcting Process}

Theme 3 of the questionnaire surveyed students' responses to the practices and consequences of the process. The correcting practices were classified into characteristics of activity, categories of gaps, and necessity of revision and comparison (Statements 5A-F), whereas Statements 5G-K focused on particular outcomes of the collaborative process. Thus, results of these items are divided into two subsections that are reported below.

\subsubsection{Practices of the Correcting Process}

The statistical analysis summarized in Table 4A shows that students strongly agreed and agreed with the correcting phases that resulted in a level of high mean $-4-$ for Statements A-F. Students responded to the "agree" and "strongly agree" that correcting errors is encouraging (Statement 5A: 68\% and 32\%) and is not time-consuming (Statement 5B: $90 \%$ and 10\%). They also concurred in their responses to rewriting the first draft after correction (Statements 5E: 74\% and 26\%) and to comparing the rewritten text with the first draft (Statements 5F: 74\% and $26 \%$ ). These responses were elaborated by the six representative students' reports of the three correcting phases as being "closely related". Nhu stated that "the correcting process is practical ... the discovering and correcting stages are the leading and constructing stages for the revision and the revision is the consolidating and synthesising stage". Lam also stated that the three correcting phases fostered skills in "interaction, searching, modification, and revision". These responses show that engaging in the CP satisfied intentionality and reciprocity in MLE as students received support and feedback from both the teacher and peers. However, Anh acknowledged that "I was less active and confident in rewriting the texts than in discovering and correcting the gaps ... revision is the most difficult task because it required more attempts to produce a good text". These responses indicate that while the discovering and correcting tasks helped create active learning and more confidence for students, the rewriting task was beyond their ability in some cases.

In addition, the study found students' strong agreement with correcting some preselected gaps. The majority of students either "agreed" or "strongly agreed" that they should not correct grammar alone (Statements 5C: 80\% and $20 \%$ ), but correct both content and grammar (Statements 5D: 45\% and 55\%). Students' preferences for targeting both grammatical errors and language issues are supported by Vasu et al.'s study (2016) reporting that Malaysian students perceived the value of teacher feedback on content, organisation and grammar. Students' strong agreement was elaborated by interviewees' opinions about the significance of amending both grammatical and nongrammatical gaps. Khoa stated: "I think that if we only correct grammar, ideas in a piece of writing are not logically linked, and thus, the texts are not comprehensible." Similarly, Hien explained: "I have found that although it is difficult to amend the content of the topic and supporting sentences, I would like to correct all kinds of errors in order to have a meaningful piece of writing"; this constitutes transcendence in MLE. 
Table 4A. Practices of the correcting process $(N=31)$

\begin{tabular}{|c|c|c|c|c|}
\hline \multirow{2}{*}{ Statements } & & \multicolumn{3}{|c|}{ Descriptive statistics } \\
\hline & & Frequency & Percent & Mean \\
\hline \multirow{2}{*}{ 5A. An encouraging activity } & Agree & 21 & 67.7 & \multirow{2}{*}{4.32} \\
\hline & Strongly agree & 10 & 32.3 & \\
\hline \multirow{2}{*}{ 5B. NOT a time-consuming activity } & Agree & 28 & 90.3 & \multirow{2}{*}{4.10} \\
\hline & Strongly agree & 3 & 9.7 & \\
\hline \multirow{2}{*}{ 5C. NOT to correct only grammar } & Agree & 25 & 80.6 & \multirow{2}{*}{4.19} \\
\hline & Strongly agree & 6 & 19.6 & \\
\hline \multirow{2}{*}{ 5D. Correcting content and grammar } & Agree & 14 & 45.2 & \multirow{2}{*}{4.55} \\
\hline & Strongly agree & 17 & 54.8 & \\
\hline \multirow{2}{*}{ 5E. Revising the first draft after correcting errors } & Agree & 23 & 74.2 & \multirow{2}{*}{4.26} \\
\hline & Strongly agree & 8 & 25.8 & \\
\hline \multirow{2}{*}{$5 \mathrm{~F}$. Comparing the revised text with the first draft } & Agree & 23 & 74.2 & \multirow{2}{*}{4.26} \\
\hline & Strongly agree & 8 & 25.8 & \\
\hline
\end{tabular}

\subsubsection{Consequences of the Correcting Process}

Table 4B presents the results of students' responses to Statements 5G-K, which elicited their perceptions of the outcomes of the CP. Students agreed and strongly agreed with using grammar accurately (Statement 5G: 65\% and $35 \%$ ), linking and developing ideas (Statement 5H: $45 \%$ and 55\%) and increasing learning motivation (Statement 5K: $71 \%$ and $29 \%$ ) as a consequence of working collaboratively with peers within and across groups. However, four students $(13 \%)$ were not sure about the effect of revising a paragraph better while the percentage of agreement and strong agreement was 55\% and 32\% (Statement 5J). This clearly indicates that engaging in the CP resulted in students' positive responses that were elaborated by the eight interviewees' ideas about the effectiveness of correction, considered as mediation of meaning in MLE. Hien stated that "correcting grammar makes the text more accurate", and Han emphasized that she was able to "learn different ideas to correct the irrelevance between the topic and supporting sentences". These responses clarify students' perceived benefits of teacher and peer feedback, on peer collaboration, task interest, and accuracy improvement (Lee, 2015; Tsui \& Ng, 2000).

Table 4B. Consequences of the correcting process $(N=31)$

\begin{tabular}{lcccc}
\hline \multirow{2}{*}{ Statements } & \multicolumn{4}{c}{ Descriptive statistics } \\
\cline { 2 - 5 } & & Frequency & Percent & Mean \\
\hline \multirow{2}{*}{ 5G. Using grammar accurately } & Agree & 20 & 64.5 & \multirow{2}{*}{4.25} \\
& Strongly agree & 11 & 35.5 & \\
\multirow{2}{*}{ 5H. Linking ideas between topic and supporting sentences } & Agree & 14 & 45.2 & \multirow{2}{*}{4.55} \\
& Strongly agree & 17 & 54.8 & \\
\hline \multirow{2}{*}{ 5I. Developing ideas in a written paragraph } & Agree & 22 & 71.0 & \multirow{2}{*}{4.29} \\
& Strongly agree & 9 & 29.0 & \\
\multirow{2}{*}{ 5J. Revising a paragraph better } & Not sure & 4 & 12.9 & \\
& Agree & 17 & 54.8 & \multirow{2}{*}{4.19} \\
& Strongly agree & 10 & 32.3 & \\
\hline \multirow{2}{*}{ 5K. Increasing motivation, confidence, enjoyment } & Agree & 22 & 71.0 & \multirow{2}{*}{4.29} \\
\hline
\end{tabular}

\section{Discussion}

From a pedagogical perspective, the correcting design was able to engage students in learning correction, which resulted in students' positive evaluation of effectiveness and strong agreement with the practices and consequences of the process. The perceived values could be attributed to multiple learning levels incorporated into the process to facilitate student engagement. The discovering and correcting tasks appear to have triggered the students' attention and activation as they were directed to pay attention to the incorrect forms of language and to act on those forms that could help them achieve a conscious level of awareness of some gaps and the corrections used to rewrite the texts. These were attested by Anh, Khoa, Han and Hien, who explained that engaging in the CP enabled them to use present and past tenses accurately, link ideas between the topic sentence and its supporting ideas, and 
especially transfer skills to writing Vietnamese literature, which are signs of MLE transcendence. The rewriting task seemed to prompt students' reflection on and use of language features as a form of output; for example, rewriting a corrected essay can affect learning positively (Polio, 2012). Nevertheless, it might challenge students with low English proficiency, as attested by Anh's case. Anh's acknowledgement of being less active and confident in rewriting the texts clarifies the claims that student engagement with WCF is affected by language ability (Zheng $\& Y u, 2018$ ) and learning tasks (Ellis, 2010). While the finding validates the idea of engaging students in working on their own gaps (Erlam et al., 2013; Lee, 2009), it also suggests the value of varying the levels of difficulty of tasks to facilitate student engagement.

Contextualizing feedback-correction practices in a socially mediated learning context may facilitate student engagement, which in turn leads to students' preferences for the joint practice between the teacher and peers. The teacher, as a mediator, appeared to have triggered students' engagement by mediational strategies. These include offering scaffolding strategies to engage students with collaborative discovering and rewriting tasks, asking questions to elicit students' corrections, and providing indirect corrections and clues to prompt students to treat gaps in their groups. In addition, collaboration with peers to perform the correcting tasks is another possible explanation for the perceived valuing of learning from and collaborating with peers. The teacher's intervention and collaboration with peers possibly led to students' perception that they benefitted from the joint practice, as they acknowledged receiving support and useful comments from the teacher and peers. These are evidence of MLE's intentionality and reciprocity. The perceived ideas indicate that responding to the teacher's mediational strategies and peers' collaboration enabled students to achieve a certain level of effective accomplishment - mediation of meaning - when working on the discovering, correcting, and rewriting tasks (Feuerstein \& Feuerstein, 1991). In other words, students were able "to do more and solve more difficult tasks than [they] can independently" (Vygotsky, 1987, p. 209), thanks to the teacher's instruction and peer collaboration. The joint correcting practices, therefore, avoided positioning students as mere recipients of passive feedback or correction. This finding corroborates students' favoring of the correcting practice of peers and the teacher (Dang, 2016; Yang et al., 2006; Zhao, 2014). However, the finding contradicts evidence of students' perception that the teacher's direct correction alone is best (Lee, 2005, 2008), as students in the present study were scaffolded to engage in the CP to process gaps via various learning tasks.

Nevertheless, intrinsic features of group-work also possibly resulted in the perceived limitations. Collaborative correction, in itself, did entail unexpected issues in some cases. Han, Nhu, Lam, and Tu considered collaborative correction as requiring large amounts of time because they occasionally experienced individuals' opposing opinions when their groups shared ideas and discussed solutions to treat gaps, despite the students' strong agreement with this was not time-consuming for correction. According to Nhu's explanations, the unequal contribution among individuals in their groups might result from mixed-ability grouping that suggests a limited level of engagement of less-capable students and an extensive engagement of more-capable peers. For example, while collaborating with peers to perform the correcting tasks, capable peers played the role of an expert who mediated less-capable peers' engagement. These comments provide important insights about the nature of social learning, which, on the one hand, may be helpful for negotiation and development, but on the other, entails time considerations and unequal contributions.

Feelings of confidence and achievement, which were experienced in targeting grammatical and nongrammatical gaps, may account for students' preferences for these two types of gaps. Opportunities for treating tenses and conjunctions, as explained by the eight students, assisted improvement in making the texts more grammatically correct. Moreover, the perceived benefits of amending ideas of the topic and supporting sentences to produce comprehensible texts might create a feeling of success and competence and show the significance of targeting these two types of gaps. Evidence of students' preferences for correcting both grammatical and nongrammatical issues align with their strong agreement with the outcomes of targeting these categories of gaps (Statements $5 \mathrm{G}-\mathrm{H})$. The finding, which shows a linkage with MLE mediation of meaning, confirms the perceived values of targeting both linguistic errors and content of written texts (Hyland \& Hyland, 2012).

Strong beliefs in learning and correcting grammar and the nature of treatable errors are possible explanations for the two classes' strong agreement with the positive outcomes of the CP (Statements 5G-K). It seems reasonable to assume that skills and experience in learning grammar in secondary schools in Vietnam might engage students in correcting tenses and conjunctions that possibly resulted in their perceived improvement. The explanation is lent support by Han and Hyland (2015), who proposed that student engagement with WCF is affected by students' beliefs and learning experiences. Another possible reason is that the errors focused on were treatable errors, such as tenses that are rule-governed, and therefore the likelihood that these might create a sense of competence in students regarding their correcting ability, as they could check the outcomes by using their textbooks. 
Challenging writing behavior is given as a reason for students' accord with - and the eight students' beliefs in - the positive outcomes of correcting nongrammatical gaps. Students could link and develop ideas for the topic and supporting sentences and rewrite a paragraph (Items $5 \mathrm{H}-\mathrm{J}$ ), as elaborated by Khoa and Hien. Although students considered correcting nongrammatical issues difficult, they preferred correcting both grammatical errors and nongrammatical gaps. The challenging learning conditions, considered as a reinforcing component, termed challenging and sharing behavior in MLE, seemed to prepare students for skills in solving novel and complex learning challenges. The explanation and evidence show a link between MLE's challenging and sharing behavior and transcendence, as the challenge of amending nongrammatical gaps and rewriting the texts together motivated students to move learning forward, which may constitute a significant contribution to the literature and future feedback research.

\section{Conclusion}

The present study has contributed new insights to the area of L2 writing and research data in three ways. First, the study has drawn on the socially mediated learning framework to operationalize teacher and peer feedback incorporated into the collaborative correcting process in EFL writing classrooms to facilitate student engagement. Second, it extends previous feedback research by engaging students in the learning process to act on their own language issues through discovery, correction, and revision, and it illustrates students' positive perceptions of their engagement with the process. Third, following feedback research in L2 studies, this study has identified that correction is beneficial to L2 writing if students are provided with opportunities to respond to their own gaps through group-work with the teacher's feedback and guidance, despite certain limitations.

The students' positive responses to the practices and consequences of the process suggest implications for L2 writing pedagogy and research data. The three correcting phases shed new light on engaging students in correction that may offer implications in L2 and English as a Foreign Language writing classrooms, with considerations of unequal contributions to group work as perceived by some students. The finding of some students' acknowledgement of being less active in and unsure about the effect of rewriting the texts suggest teachers should consider students' English proficiency to provide more support when administering the rewriting task, which might challenge low-ability students. The correcting design needs to be conceptualized based on a L2 theoretical framework, with close attention to the social and cognitive aspects of learning. Integrating teacher and peer feedback into the CP operationalized by the MLE framework indicates that the present study's theoretical conceptualization and empirical evidence might provide directions for teachers and researchers to address the issue of engagement with feedback and correction.

However, there were some limitations to this study. The findings may not be generalized to other subjects as only 31 students' responses to the questionnaire, followed up with eight students' comments in the interviews, were analyzed. The fact that only eight representative students took part in the semi-structured interview possibly imposes another limitation. Hence, future research should adopt the correcting design with a larger sample and interview more students. As explained, collaborative learning resulted in both benefits and considerations of time and unequal contributions that will be of interest for further research on the correcting design. As this study explored only students' perceptions of their engagement in the process, this sets an agenda for further research to investigate the impact of students' engagement in the process on their writing improvement.

\section{Acknowledgements}

The author would like to thank the sponsor, Monash University in Australia, for offering an International Postgraduate Research Scholarship, a Graduate Scholarship, and a Post Publication Award. She is also grateful for her supervisors' insightful comments and professional guidance and for the voluntary participation of the teacher and the students.

\section{References}

Barcelos, A. M. F. (2003). Researching beliefs about SLA: A critical review. In P. Kalaja, \& A. M. F. Barcelos (Eds.), Beliefs about SLA: New research approaches (pp. 7-33). Springer. https://doi.org/10.1007/978-1-4020-4751-0_1

Bitchener, J. (2008). Evidence in support of written corrective feedback. Journal of Second Language Writing, 17. https://doi.org/10.1016/j.jslw.2007.11.004

Dang, T. D. T. (2016). Vietnamese EFL students's perceptions of noticing-based collaborative feedback on their writing performance. English Language Teaching, 9(5), 141-153. https://doi.org/10.5539/elt.v9n5p141

Dang, T. D. T. (2019). EFL Learners' engagement in a socially mediated correcting sequence: Writing development and attitudes (Unpublished doctoral dissertation), Monash University, Australia. 
Ellis, R. (2003). Task-based language learning and teaching. Oxford University Press.

Ellis, R. (2010). Epilogue: A framework for investigating oral and written corrective feedback. Studies in Second Language Acquisition, 32(2), 335-349. https://doi.org/10.1017/S0272263109990544

Erlam, R., Ellis, R., \& Batstone, R. (2013). Oral corrective feedback on L2 writing: Two approaches compared. System, 41(2), 257-268. https://doi.org/10.1016/j.system.2013.03.004

Ferris, D. (1995). Student reactions to teacher response in multiple-draft composition classrooms. TESOL Quarterly, 29(1), 33-53. https://doi.org/10.2307/3587804

Ferris, D. (1999). The case for grammar correction in L2 writing classes: A response to Truscott (1996). Journal of Second Language Writing, 8. https://doi.org/10.1016/s1060-3743(99)80110-6

Ferris, D. (2003). Response to student writing: Implications for second language students. Lawrence Erlbaum Associates. https://doi.org/10.4324/9781410607201

Ferris, D. (2011). Treatment of error in second language student writing. The University of Michigan Press. https://doi.org/10.3998/mpub.2173290

Ferris, D., Liu, H., Sinha, A., \& Senna, M. (2013). Written corrective feedback for individual L2 writers. Journal of Second Language Writing, 22(3), 307-329. https://doi.org/10.1016/j.jslw.2012.09.009

Feuerstein, R., \& Feuerstein, R. S. (1991). Mediated learning experience: A theoretical review. In R. Feuerstein, P. S. Klein, \& A. J. Tannenbaum (Eds.), Mediated learning experience (MLE): Theoretical, psychosocial and learning implications (pp. 3-51). Freund Publishing House.

Fisher, R. (2005). Teaching children to think. Stanley Thornes.

Han, Y. (2017). Mediating and being mediated: Learner beliefs and learner engagement with written corrective feedback. System, 69, 133-142. https://doi.org/10.1016/j.system.2017.07.003

Han, Y., \& Hyland, F. (2015). Exploring learner engagement with written corrective feedback in a Chinese tertiary EFL classroom. Journal of Second Language Writing, 30(Supplement C), 31-44. https://doi.org/10.1016/j.jslw.2015.08.002

Han, Y., \& Hyland, F. (2019). Learner engagement with written feedback: A sociocognitive perspective. In K. Hyland \& F. Hyland (Eds.), Feedback in second language writing: Contexts and issues (2nd ed., pp. 247-264). Cambridge University Press. https://doi.org/10.1017/9781108635547.015

Hentasmaka, D., \& Cahyono, B. Y. (2021). Peer feedback uptakes and outcomes across EFL students' proficiency levels: A study at tertiary education in Indonesia. International Journal of Instruction, 14(3), 271-286. https://doi.org/10.29333/iji.2021.14316a

Hoang, V. V., Hoang, T. X. H., Do, T. M., \& Nguyen, Q. T. (2006). Tieng Anh 10 [English 10]. Education Publishing House.

Hyland, F. (2003). Focusing on form: Student engagement with teacher feedback. System, 31(2), 217-230. https://doi.org/10.1016/S0346-251X(03)00021-6

Hyland, K., \& Hyland, F. (2012). "You could make this clearer": Teachers' advice on ESL academic writing. In H. Limberg, \& M. A. Locher (Eds.), Advice in discourse (pp. 53-71). John Benjamins Publishing Company. https://doi.org/10.1075/pbns.221.05hyl

Jacobs, G. M. (2006). Issues in implementing cooperative learning. In S. G. McCafferty, G. M. Jacobs, \& C. Iddings (Eds.), Cooperative learning and second language teaching (pp. 30-47). Cambridge University Press.

Kim, Y., Choi, B., Kang, S., Kim, B., \& Yun, H. (2020). Comparing the effects of direct and indirect synchronous written corrective feedback: Learning outcomes and students' perceptions. Foreign Language Annals, 53(1), 176-199. https://doi.org/10.1111/flan.12443

Lee, I. (2005). Error correction in the L2 writing classroom: What do students think? TESL Canada Journal, 22(2), 1-16. https://doi.org/10.18806/tesl.v22i2.84

Lee, I. (2008). Understanding teachers' written feedback practices in Hong Kong secondary classrooms. Journal of Second Language Writing, 17(2), 69-85. https://doi.org/10.1016/j.jslw.2007.10.001

Lee, I. (2009). Ten mismatches between teachers' beliefs and written feedback practice. ELT Journal, 63(1), 13-22. https://doi.org/10.1093/elt/ccn010 
Lee, I. (2015). Peer feedback in second language writing: Investigating junior secondary students' perspectives on inter-feedback and intra-feedback. System, 55, 1-10. https://doi.org/10.1016/j.system.2015.08.003

Leech, N., Barrett, K. C., \& Morgan, G. A. (2005). SPSS for intermediate statistics: Use and interpretation (2nd ed.). Lawrence Erlbaum. https://doi.org/10.4324/9781410611420

Leki, I. (2006). "You cannot ignore": L2 graduate students' response to discipline-based written feedback. In F. Hyland, \& K. Hyland (Eds.), Feedback in second language writing: Contexts and issues (pp. 266-286). Cambridge University Press.

Montgomery, J. L., \& Baker, W. (2007). Teacher-written feedback: Student perceptions, teacher self-assessment, and actual teacher performance. Journal of Second Language Writing, 16(2), 82-99. https://doi.org/10.1016/j.jslw.2007.04.002

Pawlak, M. (2014). Error correction in the foreign language classroom: Reconsidering the issues. Springer. https://doi.org/10.1007/978-3-642-38436-3

Philp, J., \& Duchesne, S. (2016). Exploring engagement in tasks in the language classroom. Annual Review of Applied Linguistics, 36, 50-72. https://doi.org/10.1017/S0267190515000094

Polio, C. (2012). The relevance of second language acquisition theory to the written error correction debate. Journal of Second Language Writing, 21(4), 375-389. https://doi.org/10.1016/j.jslw.2012.09.004

Poole, D. (2008). Interactional differentiation in the mixed-ability group: A situated view of two struggling readers. Reading Research Quarterly, 43, 228-250. https://doi.org/10.1598/RRQ.43.3.2

Qi, D. S., \& Lapkin, S. (2001). Exploring the role of noticing in a three-stage second language writing task. Journal of Second Language Writing, 10(4), 277-303. https://doi.org/10.1016/S1060-3743(01)00046-7

Ruegg, R. (2014). The effect of peer and teacher feedback on changes in EFL students' writing self-efficacy. The Language Learning Journal, 46(2), 87-102. https://doi.org/10.1080/09571736.2014.958190

Ruegg, R. (2015). The relative effects of peer and teacher feedback on improvement in EFL students' writing ability. Linguistics and Education, 29(Supplement C), 73-82. https://doi.org/10.1016/j.linged.2014.12.001

Ruegg, R. (2017). Learner revision practices and perceptions of peer and teacher feedback. Writing \& Pedagogy, 9, 275-300. https://doi.org/10.1558/wap.33157

Saito, H. (1994). Teachers' practices and students' preferences for feedback on second language writing: A case study of adult ESL learners. TESL Canada Journal, 11(2), 46-68. https://doi.org/10.18806/tesl.v11i2.633

Storch, N., \& Wigglesworth, G. (2010). Students' engagement with feedback on writing: The role of learner agency/beliefs. In R. Batstone (Ed.), Sociocognitive perspectives on language use and language learning (pp. 166-185). Oxford University Press.

Tasdemir, M. S., \& Yalcin Arslan, F. (2018). Feedback preferences of EFL learners with respect to their learning styles. Cogent Education, 5(1), 1481560. https://doi.org/10.1080/2331186X.2018.1481560

Truscott, J. (1996). The case against grammar correction in L2 writing classes. Language Learning, 46. https://doi.org/10.1111/j.1467-1770.1996.tb01238.x

Truscott, J. (2007). The effect of error correction on learners' ability to write accurately. Journal of Second Language Writing, 16(4). https://doi.org/10.1016/j.jslw.2007.06.003

Tsui, A. B. M., \& Ng, M. (2000). Do secondary L2 writers benefit from peer comments? Journal of Second Language Writing, 9(2), 147-170. https://doi.org/10.1016/S1060-3743(00)00022-9

Ur, P. (1996). A course in language teaching: Practice and theory. Cambridge University Press.

Ur, P. (2009). Grammar practice activities: A practical guide for teachers. Cambridge University Press.

Vasu, K., Ling, C. H., \& Nimehchisalem, V. (2016). Malaysian tertiary level ESL students' perceptions toward teacher feedback, peer feedback and self-assessment in their writing. International Journal of Applied Linguistics and English Literature, 5, 158-170. https://doi.org/10.7575/aiac.ijalel.v.5n.5p.158

Vygotsky, L. (1978). Mind in society: The development of higher psychological processes. Harvard University Press.

Vygotsky, L. (1987). The development of scientific concepts in childhood In R. W. Rieber, \& A. S. Carton (Eds.), The collected works of L. S. Vygotsky (Vol. 1, Problems of general psychology, pp. 167-241). Plenum Press. https://doi.org/10.1007/978-1-4613-1655-8_9 
Westmacott, A. (2017). Direct vs. indirect written corrective feedback: Student perceptions. Íkala, 22(1), 17-32. https://doi.org/10.17533/udea.ikala.v22n01a02

Williams, M., \& Burden, R. L. (1997). Psychology for language teachers: A social constructivist approach. Cambridge University Press.

Yang, M., Badger, R., \& Yu, Z. (2006). A comparative study of peer and teacher feedback in a Chinese EFL writing class. Journal of Second Language Writing, 15(3), 179-200. https://doi.org/10.1016/j.jslw.2006.09.004

Zhao, H. (2014). Investigating teacher-supported peer assessment for EFL writing. ELT Journal, 68(2), 155-168. https://doi.org/10.1093/elt/cct068

Zheng, Y., \& Yu, S. (2018). Student engagement with teacher written corrective feedback in EFL writing: A case study of Chinese lower-proficiency students. Assessing Writing, 37, 13-24. https://doi.org/10.1016/j.asw.2018.03.001

\section{Appendix A}

The Closed-ended Questionnaire (Dang, 2019)

For each question from 1-4, circle or tick $\checkmark$ the appropriate statement to answer the questions

1. To what extent do you find correcting errors in English writing effective?
A. Poor
B. Not so good
C. Good
D. Very good
E. Excellent

2. How helpful is error correction to enhance your ability to correct errors?
A. Poor
B. Not so good
C. Good
D. Very good
E. Excellent

3. How helpful is error correction to enhance your ability to write a paragraph accurately?
A. Poor
B. Not so good
C. Good
D. Very good
E. Excellent

4. To correct errors in your writing, do you prefer ....?
A. Self-correction
B. Teacher's correction
C. Pairs correction
D. Group correction with teacher's assistance
E. Group correction (3-4 students)

5. To what extent do you agree with the following statements? Tick $\checkmark$ the appropriate box to the right of the statement. 
A. Correcting errors is an encouraging activity.

B. Correcting errors in writing is NOT a time-consuming activity.

C. You should NOT correct only grammatical errors.

D. You should correct irrelevant ideas between the topic and supporting sentences and grammar of pieces of writing.

E. You need to revise the first draft after correcting errors.

F. You need to compare the rewritten text with the first draft.

G. Correcting grammar helps you use tenses and conjunctions more accurately

in a written paragraph.

H. Correcting non-grammatical gaps helps you know how to link ideas between the topic and supporting sentences.

I. Correcting practices help you know how to develop ideas in a written paragraph.

J. Correcting practices enable you to rewrite a paragraph better.

$\mathrm{K}$. You have more confidence, enjoyment, and motivation after learning correction.

\section{THANK YOU FOR COMPLETING THE QUESTIONNAIRE!}

\section{Appendix B}

Student Participants and Their English Scores (Dang, 2019)

\begin{tabular}{ccccccccc}
\hline \multirow{2}{*}{ Class } & \multirow{2}{*}{ Total } & \multicolumn{2}{c}{ Gender } & \multicolumn{4}{c}{ Scores in the 1st semester exam } \\
& & Male & Female & $\leq 3$ & $3.5-4.75$ & $5-6.75$ & $7-8.75$ & $9-10$ \\
\hline Collaborative-co & 31 & 17 & 14 & 1 & 0 & 2 & 16 & 12 \\
$\quad$ rrection & $100 \%$ & 54.48 & 45.16 & 3.2 & 0 & 6.5 & 51.6 & 38.7 \\
\hline
\end{tabular}

\section{Appendix C}

Writing and Correcting Topics (Dang, 2019)

\begin{tabular}{ll}
\hline Number & Writing and Correcting Topics \\
& Phase 1: Students learn to write in groups in their writing classes (morning sessions) \\
& Phase 2: Correcting treatment (afternoon sessions) \\
2 & A paragraph to describe one of the most popular events/celebrations in Vietnam \\
3 & A letter to tell your friend about your past memorable activities \\
4 & A paragraph to describe your favourite school \\
5 & Picture description: the boy and the wallet \\
6 & Picture description: the fox and the grapes \\
7 & A letter of invitation \\
8 & A letter of acceptance \\
\hline
\end{tabular}

\section{Appendix D}

Correction Guide (Dang, 2019) adapted from Yang et al. (2006)

Use the following suggestions to discover gaps and discuss some ways to correct the identified gaps in your pieces of writing in your group. You are encouraged to provide feedback and give more than one solution to treat grammatical and nongrammatical gaps.

\section{Non-grammatical issues}

- Does the writer introduce the topic of the letter or description? Yes/No 
- If no, suggest the ideas to introduce the topic of the letter or description.

- If yes, circle it and check a $\sqrt{ }$ after the sentence.

- Is there a topic sentence in each paragraph? Yes/No

- Point out the paragraph without a topic sentence. Paragraph

- Suggest a topic sentence for the paragraph.

- Are ideas relevant to the topic sentence? If you think the ieas are not appropriate, please suggest ideas that are more relevant.

\section{Grammatical errors}

- Is the use of tense correct?

- If yes, check a $\sqrt{ }$ after the correct tense.

- If no, provide corrections.

- Does the writer use appropriate conjunctions (i.e., because, although, but) to link ideas?

- If yes, check a $\sqrt{ }$ after the correct conjunction.

- If no, provide corrections.

\section{Appendix E}

\section{AN EXAMPLE OF CODING STUDENTS' RESPONSES}

\begin{tabular}{|c|c|c|}
\hline MLE's criteria & Category of MLE & Examples of responses \\
\hline Intentionality & $\begin{array}{l}\text { - The teacher's scaffolding strategies: } \\
\text { - eliciting corrections via questions and answers } \\
\text { and/or } \\
\text { - providing indirect or direct feedback, suggestions, } \\
\text { and instructions } \\
\text { - } \quad \text { The scaffolded correcting design }\end{array}$ & $\begin{array}{l}\text { We received useful comments from the teacher and friends. } \\
\text { The teacher's intervention in groups to distinguish between } \\
\text { correctness and incorrectness is very beneficial. } \\
\text { the correcting process is practical ... the discovering and } \\
\text { correcting stages are the leading and constructing stages for the } \\
\text { revision and the revision is the consolidating and synthesising } \\
\text { stage. }\end{array}$ \\
\hline Reciprocity & $\begin{array}{l}\text { The interactive and collaborative practices of } \\
\text { feedback and correction that maximize students' } \\
\text { responses to feedback to process gaps. }\end{array}$ & $\begin{array}{l}\text { We had opportunities to work with friends to correct the } \\
\text { identified gaps, and we learnt the corrections from friends in our } \\
\text { group and other groups through their presentations. }\end{array}$ \\
\hline $\begin{array}{l}\text { Mediation } \\
\text { meaning }\end{array}$ & $\begin{array}{l}\text { An effective accomplishment, mediated by students' } \\
\text { responsive actions to discover and correct gaps and } \\
\text { rewrite the corrected texts. }\end{array}$ & $\begin{array}{l}\ldots \text { consolidate present and past tenses and use conjunctions to } \\
\text { link ideas in a piece of writing. }\end{array}$ \\
\hline Transcendence & $\begin{array}{l}\text { Students' ability to transfer knowledge of correction } \\
\text { to the rewriting of the texts or for using language } \\
\text { features correctly in the rewritten texts. }\end{array}$ & $\begin{array}{l}\text { know how to connect with Vietnamese literature writing, } \\
\text { especially the topic sentence and its supporting ideas. }\end{array}$ \\
\hline
\end{tabular}

\section{Copyrights}

Copyright for this article is retained by the author(s), with first publication rights granted to the journal.

This is an open-access article distributed under the terms and conditions of the Creative Commons Attribution license (http://creativecommons.org/licenses/by/4.0/). 